\title{
This is Literacy! Reading of photographs in research on San students' literacy in a Remote Dweller School in Botswana
}

\author{
AFFILIATION Communication and Study Skills Unit, University of Botswana \\ LONE E. KETSITLILE Communication and Study Skills Unit, University of \\ Botswana
}

Introduction

I discuss here part of my larger study which investigated what San students and their non-San friends in a Remote Area Dweller (RAD) Junior Secondary School in Botswana understand as literacy in school and at home. A narrative case study approach was used to gain an in-depth understanding of what students' value and understand by literacy. Findings across participants' stories revealed that they saw literacy as those things that had value to them and these influenced how they read 'the word' and 'the world'. Storytelling, games, singing, knowledge of different plants, basket weaving and sculpting were variously identified as literacy by the six San and Tswana participants.

\section{Purpose of the study}

The purpose of this discussion paper is to enquire about the following question: What do San children value and find meaningful in their home and school environments? How does this relate to the possibilities for literacy learning? This work is taken from my PhD study (Ketsitile, 2009). This larger study examines the struggles of San children in a difficult schooling environment where they battle with speaking, reading and writing challenges, in English particularly, as well as the disparaging views of San children held by many of the teachers in the school. The students struggle to find points of connection and interest with school work that bears no relation to their out-ofschool knowledge and family practices. Gonzalez, Moll and Amanti (2001) talk of funds of knowledge as literacy that children bring to schools. They encourage teachers to recognize and tap from such knowledge. Clearly, this was not being done at this Junior Secondary School and these photpgraphs start to examine what these out of school interests and knowledge might be. My $\mathrm{PhD}$ research explores these concerns from other angles as well, including the recording and discussion of the narrative resources that these children get from the stories their parents 
and other elders have told them over the years, none of which receive any recognition from the school, in the classroom .

\section{Participants}

I employed what researchers call snowball, chain or network sampling to find my participants (Merriam, 1998). I spoke to two informants firstly, who then introduced me to others. I told the participants that I would like to work with them closely by interviewing, observing and listening to what they had to say about their past and present schooling experiences and what they valued in their school and out-of-school lives. This would help me to understand their views of literacy in and out of school. To provide anonymity I have given them different names and in many cases ones that are English translations of their Setswana names. My non-San informants Love and Peace told me stories about the San students they knew. I asked them to find San students who might collaborate with me as informants or as co-participants. They introduced me to Done and News who agreed to work as San informants. Then Done and News introduced me to Mr. President who agreed to be a participant. ${ }^{5} \mathrm{He}$ in turn introduced me to his best friend, Knowledge who agreed to participate. Later Done and News introduced Happy to me and she agreed to participate. Love and Peace told me some stories about Trust. That led to asking Trust to participate and he agreed. Also, Love and Peace introduced me to Drought who agreed to be a participant. After I interviewed Drought, she led me to Receiver because she thought she was a better singer than her. In sum, I collected data from 2 nonSan informants (Love and Peace), 2 San informants (Done and News) and 6 participants (Mr. President, Knowledge, Happy, Trust, Drought, Receiver). I have summarized some information about these children in the table below.

Table 1: Participants and Informants Profile

\begin{tabular}{l|c|l|l}
\hline \multicolumn{1}{c|}{ Name } & Age & \multicolumn{1}{|c}{ Gender } & \multicolumn{1}{c}{ Form/Grade } \\
\hline Mr. President (participant) & 15 & Male & Form One $=$ Grade 8 \\
\hline Knowledge (participant) & 14 & Male & Form One $=$ Grade 8 \\
\hline Happy (participant) & 14 & Female & Form One $=$ Grade 8 \\
\hline Drought (participant) & 15 & Female & Form One $=$ Grade 8 \\
\hline Receiver (participant) & 16 & Female & Form 2 = Grade 9
\end{tabular}

${ }^{5}$ He had told me his name was the same name as a former Botswana leader. From that day, I started to call him Mr. President whenever I met him around school. 


\begin{tabular}{l|c|l|l}
\hline \multicolumn{1}{c|}{ Name } & Age & \multicolumn{1}{|c|}{ Gender } & \multicolumn{1}{c}{ Form/Grade } \\
\hline Trust (participant) & 14 & Male & Form One = Grade 8 \\
\hline Done (informant) & 14 & Female & Form One $=$ Grade 8 \\
\hline News (informant) & 15 & Male & Form One $=$ Grade 8 \\
\hline Love (informant) & 14 & Female & Form One = Grade 8 \\
\hline Peace (informant) & 14 & Male & Form One = Grade 8
\end{tabular}

\section{Photography as a method of data collection}

Photography is an important method of data collection (Grbich, 2007). A given photograph can be 'read' in many ways depending on one's culture, background and beliefs. According to Clandinin and Connelly (2000: 115) photographs help us to construct our lives and "are rich sources of field texts for the construction of social narratives". I gave the six San participants disposable cameras to take pictures in their environment and school. Love, one of my non-San informants showed the others how to use the cameras. After that, each student took some pictures as a test. Then, I asked them to take pictures of the things that represented literacy or had meaning to them.

After the pictures were developed I met with each student to ask them to explain why they took a particular picture. This further shed light on students' experiences, perceptions and ways in which they make meaning. In this activity, the students described what was in the photograph and why they took the photograph.

Pink (2006) pointed out that as researchers, we can make a lot of sense from visuals and photographs. I asked enquiring and open-ended questions, like, "What is going on in this picture?" and "Why did you take this picture?" The value of photography is that it allows for the visual image to be 'read' according to a given culture and within a given historical context, thus, providing a rich source of research information (Grbich, 2007). 


\section{Making meaning from selected photographs}

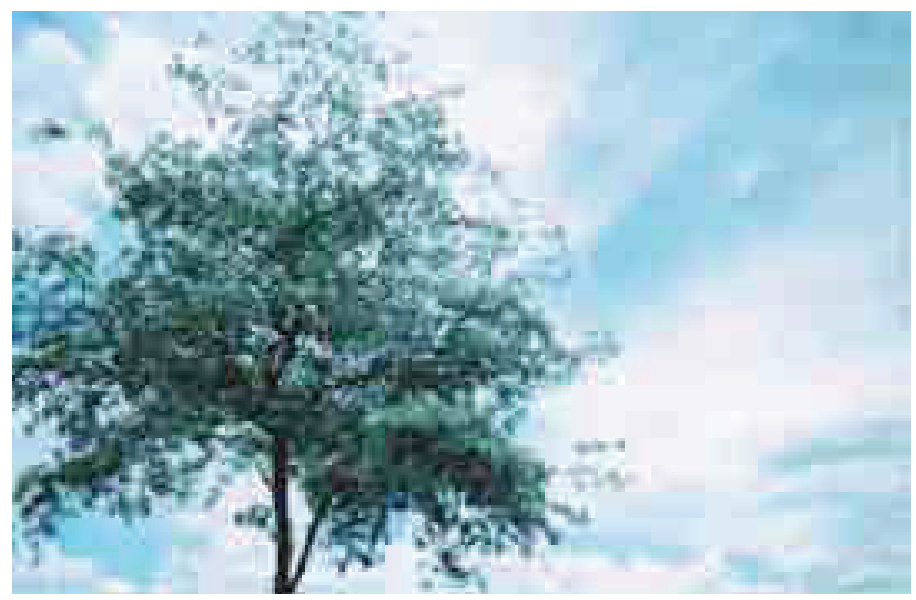

Figure 1: Plant used in successful hunting

Mr. President explained a photograph where he had taken some very green plants. To me, they looked like ordinary plants but, he explained that the plant was very important in hunting. For a successful hunt, one needs to burn the root of the plant and then tie it to some branches to trap small animals like rabbits. "If we were taught such interesting knowledge in science, students from Gaborone and other places would benefit. But, I do not think they will be interested," reasoned Mr. President. "They look down on such knowledge," he explained.

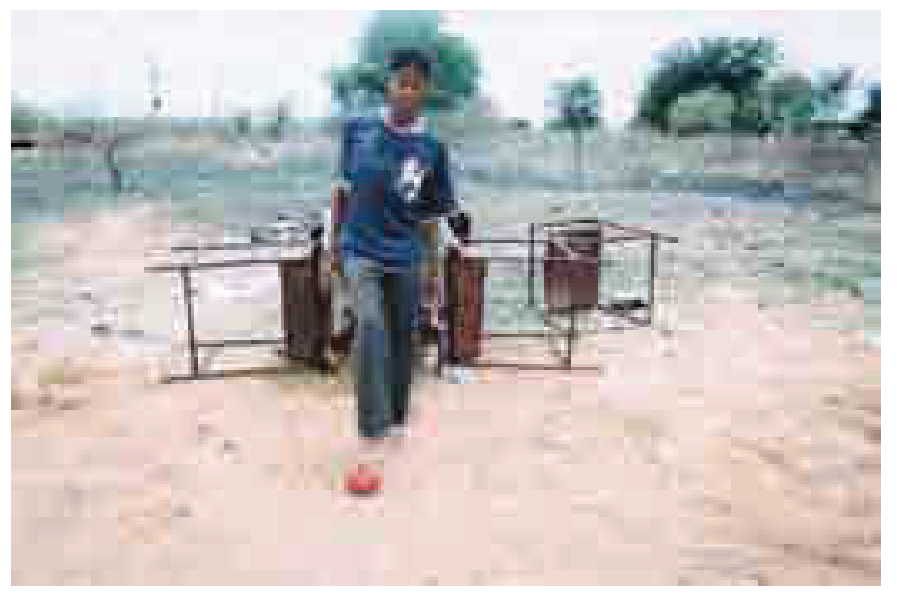

Figure 2: Knowledge's friend Tshepho in 'Germany' 
Behind the hostels was a barren, dusty field that the San students called 'Germany.' 'Germany' was much smaller than the school's official sports field and from close observation, I could tell Knowledge and his friends had put a lot of work into it. They had cleared all the grass from the field and erected some pillars that proudly represented football posts. Two or three balls made of cloth, plastic, paper; anything the boys came across could be seen in the middle of the field. 'Germany' was a safe haven for these boys. Knowledge explained that playing was very important to him and his friends.

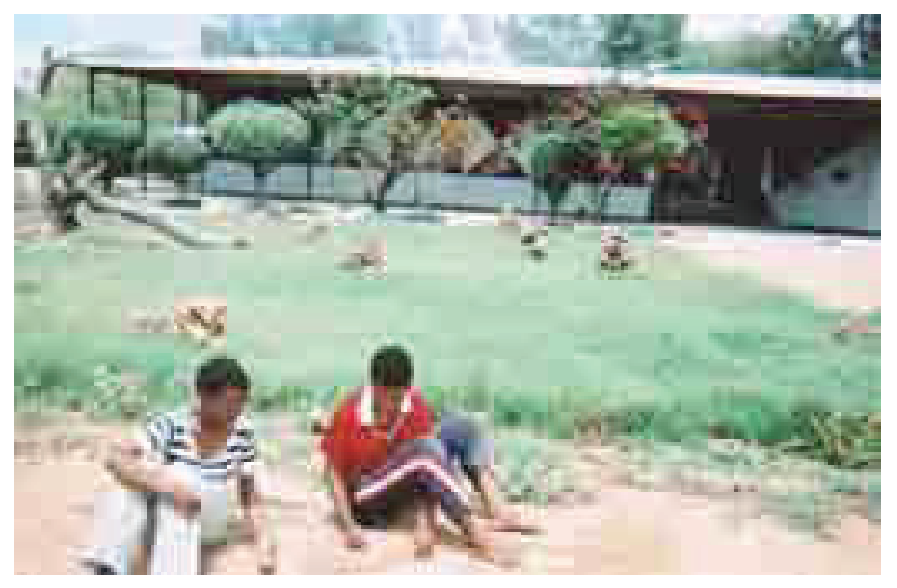

Figure 3: Two girls playing Morabaraba game

Happy loved this game so much because it was fun and exciting. She missed home because she played a lot with her siblings and cousins during the school holidays. She felt that there was not much play time in school.

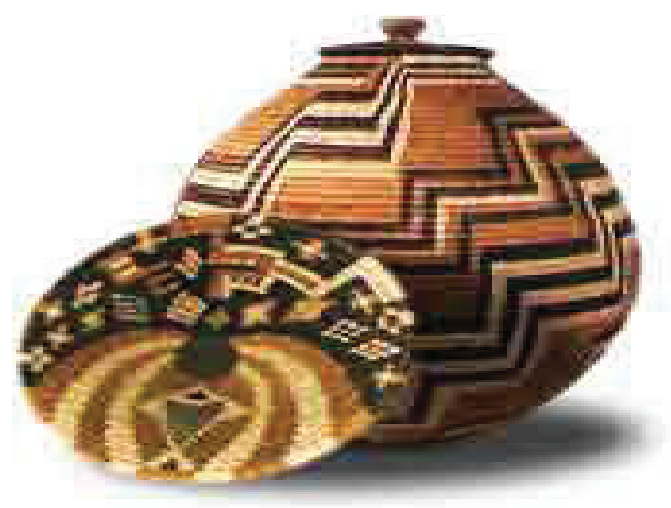

Figure 4: Traditional baskets 
This is literacy to Receiver as she learnt how to collect the grass needed for making the different baskets. In addition, her mother and aunts taught her how to weave and read the patterns in the baskets.

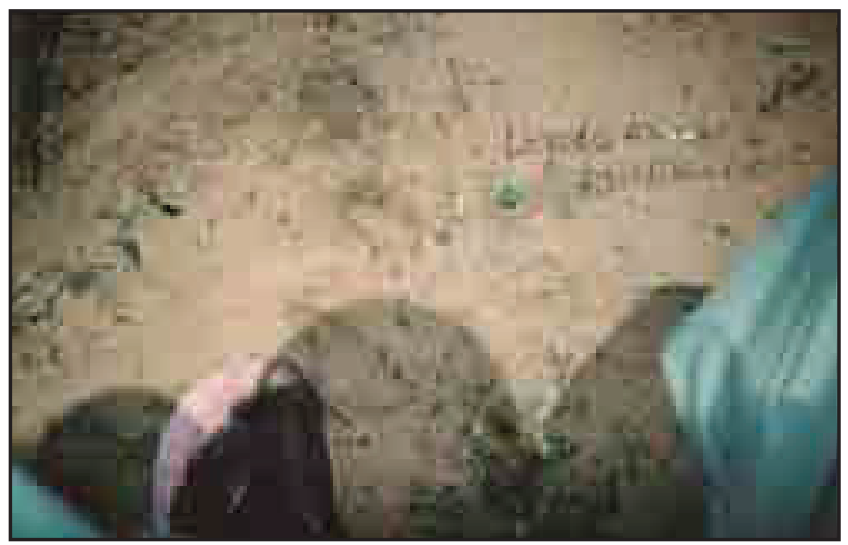

Figure 5: Lerete la ga Rankurunyane

Trust's view of literacy included knowledge of the different plants. He showed me a photograph of a plant he took called Lerete la ga Rangkurunyane. The plant is used medicinally to protect a newborn baby from harm. The plant is ground into powder and given to the baby in liquid form. Some of the powder is applied on the baby's head.

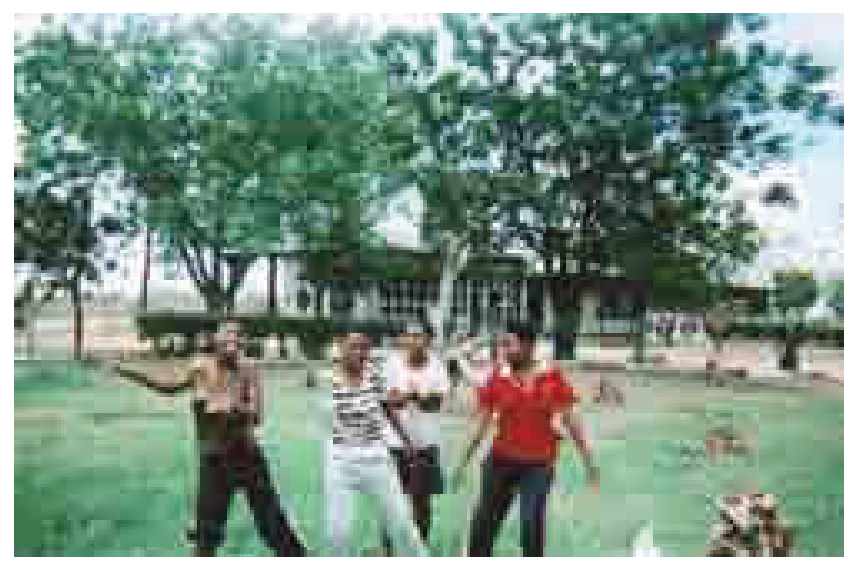

Figure 6: Drought's friends singing 'Morabaraba' song 
One of the photographs that Drought took to help me understand what literacy meant to her was of a group of her friends singing the Morabaraba song. She took this photograph because she loves singing and she also values the messages in songs. She sang me a song on passion killings that warned Batswana on the dangers of passion killings. Drought thought the song important because it can help to reduce passion killings and suicide. Unfortunately she was nervous about singing at school because the non-San students would laugh.

\section{Conclusion}

Participants' ways of reading and knowing the word and the world need to be included in the school curriculum for the benefit of not only San students but non-San ones in Botswana. In addition, appropriate pedagogic strategies that draw on these resources and build comfortable bridges to standard school knowledge need to be adopted in classrooms to enable San children to succeed in school.

\section{References}

Clandinin, D.J., \& Connelly, F.M. 2000. Narrative inquiry: Experience and story in qualitative research. San Francisco: Jossey-Bass Publishers.

Gonzalez, M., Moll, L.G., \& Amanti, C. 2001. Funds of knowledge for teaching: Using a qualitative approach to connect homes and classrooms. Theory into practice, 31(2): 132-142.

Grbich, C. 2007. Qualitative data analysis: An introduction. Thousand Oaks, CA: Sage.

Ketsitlile, 1. E. 2009. San Junior Secondary Students' understandings of literacy in school and at home: A case study. Unpublished PhD thesis. University of Athens, Georgia.

Merriam, S.B. 1998. Qualitative research and case study applications in education. San Francisco: Jossey-Bass Publishers.

Pink, S. (2006). The future of visual anthropology: engaging the senses. New York: Routledge. 